\title{
The Results of Poverty Alleviation Work in Practice in Huangpi District, Wuhan
}

\author{
Ziyi Sun ${ }^{1, *}$
}

\author{
${ }^{1}$ King 's College London \\ *Email: ziyi.sun@kcl.ac.uk
}

\begin{abstract}
Poverty is a global problem. How to accurately formulate appropriate poverty alleviation policies to help the poor get rid of poverty is essential. This paper selects Huangpi District, one of the most representative poverty-stricken areas in Wuhan City, to research the effect of poverty alleviation policy. Through interviews, questionnaires, and visits, it finds that the poverty alleviation policy has had a positive impact on Huangpi. Poor people were more satisfied with their lives as their income increased and their living conditions were improved. However, there are still the potentials factors which will cause poverty again, including the lack of education and the influence of natural disasters and disease. This research further proposes measures to counter these risks. For instance, a diversified funding risk mechanism should be established with the help of national financial policies, social funding from enterprises, and donations from individuals. This research will help promote the development of precise poverty alleviation.
\end{abstract}

\section{Keywords: Poverty alleviation policy, Huangpi District, Living condition, Income, Poverty return}

\section{INTRODUCTION}

With the implementation of reform policy and opening up, hundreds of millions of Chinese people have emerged from the mire of poverty and are on the road to prosperity. At the present stage, China's poverty eradication efforts are in full swing and have made significant achievements, with increasingly more people being lifted out of poverty.

However, there is still a long way to go to achieve the essential socialist goal of "common prosperity." It is to free poor people from the dilemma of living in poverty completely, not temporarily. This paper evaluates the effect of the poverty eradication policy in Huangpi District in Wuhan and the potential risks of returning to poverty. Huangpi is located directly north of Wuhan and accounts for $1 / 4$ of the area and $1 / 8$ of the population of Wuhan City. It is the largest and most populous urban area in Wuhan. The deprived area of Huangpi covers an area of 1,181.6 square kilometres or $45 \%$ of the old area of Wuhan. Eight of the 19 streets (townships) in the district are significant areas of poverty. There are now 88 major poor villages established and registered, which accounts for $32.5 \%$ of the city. The poor population is 23,333 people, which is $20.4 \%$ of the city [1]. Huangpi is a large crop-producing area and an area with a large population and the focus of Wuhan's poverty alleviation goals. Due to the high population density and wide variation in resources, it is not easy to eradicate poverty in Huangpi.

There were a couple of research on poverty alleviation. Merwe's study focused on the investigation of pro-poor policies in inner-city areas [2]. He made several recommendations for pro-poor work in urban settings based on a detailed study of the current state of urban poverty in Zimbabwe, noting, in particular, the indispensable role of churches in the process of poverty alleviation. In 2010, Muhammad et al. noted the positive role of theoretical support in poverty alleviation [3]. Their research showed that good governance is an essential guiding force in addressing poverty in Bangladesh in the context of its poverty situation and previous poverty alleviation efforts. Gunhidzirai and other researchers indicated that informal entrepreneurship as a mechanism for poverty reduction in Zimbabwe could be used to a lesser extent, based on an explanation of the opportunities and challenges it faces [4].

Due to the differences between the current social situation at home and abroad, it was easy to see that the policy impact on poverty reduction issues remains high in many Western countries. They more focused on the groups that suffer from poverty as a result of disasters.

However, in the Chinese context, Professor Wang found that poverty in China is the product of multiple 
correlations between poverty alleviation, economic development, and rural development [5]. Therefore, to design and plan an excellent economic development model is the basis for poverty eradication. Moreover, Jia et al. insightfully summarized the problem of poverty and its causes from the perspective of social welfare theory. They argued that social support is necessary under the social welfare system [6]. At the same time, they argued that many of the current poor in China are mainly affected by poverty awareness and cultural poverty, which have reduced the enthusiasm of poor groups for poverty alleviation and their participation in poverty alleviation. $\mathrm{Xu}$ et al. studied the poverty alleviation practices in China's western regions through an empirical survey [7]. They analyzed their involvement in poverty alleviation activities and concluded that they were involved in poverty alleviation activities. China's ability to bring technology, finance and other resources is key to poverty alleviation in poor areas.

In contrast to foreign researchers, many domestic researchers have been directly involved in research on precise poverty alleviation mechanisms. Although many reasonable conclusions and recommendations have been made, the findings are still minimal. They focused on the identification mechanism of the poor rather than the effect of policy. This paper would fill the knowledge gap in this aspect.

Through questionnaires and interviews, this research finds that the poverty alleviation policy in the Huangpi has yielded promising results, with the number of poor areas decreasing and the number of poor people continuing to fall. Most of them were satisfied with their lives with higher income and better living conditions. However, the challenges of poverty alleviation remained daunting. There are potential risks of returning to poverty, including the lack of education, natural disaster, and disease. This research aims to facilitate the development of an overall work plan for other poverty alleviation policy in the future.

\section{RESEARCH METHOD}

This research turned attention to the effect of poverty alleviation work in Huangpi. Given the high population density and the complexity of the neighborhoods in Huangpi District, it would be too costly to conduct visits throughout the district, so it selected as many core representative streets and villages as possible for analysis and data statistics. Four streets and towns were selected: Mulan Township, Lijiaji Street, Caidian Street and Wangjiahe Street.

This paper used questionnaires and interviews and took complete account of current social hotspots such as "Big Data," "Artificial Intelligence," and "Industry 4.0" in its analysis and research.
The questionnaire and interviews focused on the following areas and questions.

1) To what extent has your family's productive life changed through precise poverty alleviation compared to the past?

2) What is your family's primary source of income at present?

3) What do you think are the leading causes of poverty in your family?

4) Which of the following models do you think is more effective in solving the local poverty situation?

\section{POSITIVE EFFECT OF THE POVERTY ALLEVIATION POLICY}

\subsection{Living Conditions of the Family}

\subsubsection{Income Status and Sources of Households Leaving Poverty}

To measure annual expenditure in the questionnaire, the interviewer first confirmed with the poor households the various expenditure matters and specific expenditures of the previous year. Then the interviewer combined the annual expenditure. For the measurement of the annual net income of the poor households, the interviewer first confirmed with the poor households the various sources of income and specific income of the previous year. Then the interviewer combined the annual income. The system of indicators and statistical calibre of expenditure items includes food, medical care (after reimbursement), education, gift expenses, daily living expenses, and pension and cooperative medical insurance premiums. The system of indicators and statistical calibre of income sources includes general income from labour, income from wages, income from agricultural operations and income from non-agricultural operations.

Income from maintenance, income from low-income insurance, income from old-age pensions or retirement pensions, and income from subsidies (relief, agricultural and others).

Of the 221 poor households, 21 were low-income poor households, 11 were five-poor households, and the remaining 189 were all out of poverty. The most significant number of poor households in the sample was 4 , with an average household size of 3.5 and the most significant household size was 7 (the questionnaire was based on the number of household members in the household register. The actual number of people living together varied slightly) and the smallest household size was 1. In terms of income, the per capita annual household income of the survey sample was $\$ 9217.4$.

Work was the most important source of income for poor households. The total income from labour accounted 
for $64.5 \%$ of the total annual income of poor households, the highest proportion. This showed that the economy of work and transfer of employment is crucial to escape poverty. This was followed by agricultural income at $13.7 \%$, which showed that agricultural income was a basic income and that increased support for agricultural production remained an element of poverty alleviation. However, agricultural income was still slightly modest compared to the income from work, so careful consideration needs to be given to develop rural industries.

In the survey sample, only ten five-guarantee households and six low-guarantee households (with agricultural income) had no wage income, which means that ten five-guarantee households could only rely on relief income such as pensions and low-guarantee payments as a source of income, which represented the most challenging group of poor households. This also illustrated the importance of guaranteed poverty alleviation, such as low-income assistance to maintain the primary livelihood of the particular hardship households. In addition, the questionnaire also addressed the issue of local poverty alleviation industries. Most poor households participated in short-term training in planting or farming organized by the poverty alleviation office. The few poor households that did not participate lacked labour due to disability or illness. In addition, most poor households received breeding seedlings (similar to chickens, ducks, cows and sheep) from the industrial poverty alleviation project, and the highest amount of support received was RMB 5,000. Among them, two poor households took out loans of RMB 40,000 for industrial development.

\subsubsection{Current Housing Situation of Households Leaving Poverty}

221 households from the 746 households in the four priority poverty areas were selected to see the change of housing types.

Table 1. Housing conditions of the poor households in Huangpi District

\begin{tabular}{|c|c|c|c|c|}
\hline & Building & Bungalows & Adobe house & Other \\
\hline Mulan Township & 1 & 56 & 11 & 0 \\
\hline Li Jia Ji Street & 0 & 49 & 3 & 0 \\
\hline Canadian Street & 0 & 34 & 8 & 4 \\
\hline Wangjiahe Street & 1 & 42 & 12 & 0 \\
\hline
\end{tabular}

\subsection{The Satisfaction of the Households Leaving Poverty}

\subsubsection{Satisfaction with Current Housing}

For the survey on housing satisfaction of households who have escaped poverty, $81 \%$ of the households who have escaped poverty were delighted with their current housing conditions, 14\% were relatively satisfied, and 5\% were generally satisfied. Relatively good housing conditions allowed villagers to live and work in peace and contentment. However, some villagers had a desire to further improve their current housing situations by increasing their income (see Table 2).

Table 2. Housing satisfaction of the poor households in Huangpi District

\begin{tabular}{|c|c|c|c|c|}
\hline & Very satisfied & More satisfied & General & Not satisfied \\
\hline Mulan Township & 52 & 11 & 4 & 0 \\
\hline Li Jia Ji Street & 46 & 4 & 2 & 2 \\
\hline Canadian Street & 33 & 6 & 5 & 1 \\
\hline Wangjiahe Street & 36 & 13 & 4 & 2 \\
\hline
\end{tabular}

Table 3. Income satisfaction of the poor households in Huangpi District

\begin{tabular}{|c|c|c|c|c|}
\hline & Very satisfied & More satisfied & General & Not satisfied \\
\hline Mulan Township & 12 & 32 & 21 & 1 \\
\hline Li Jia Ji Street & 8 & 31 & 12 & 2 \\
\hline Canadian Street & 33 & 6 & 5 & 1 \\
\hline Wangjiahe Street & 36 & 13 & 4 & 3 \\
\hline
\end{tabular}




\subsubsection{Satisfaction with Current Income}

As Table 3 shows, in terms of satisfaction with income, both the poor and non-poor households were concentrated on the "relatively satisfied" and "average" categories, with a combined percentage of $82.5 \%$ for poor households. The proportion of "very satisfied" was not high, with about $15.2 \%$. Overall, the households that had left poverty are optimistic about their current household income.

\subsection{The Aspirations of the Households Leaving Poverty}

Based on the data analysis in 3.1 and 3.2 above, the following analyses the demands of the households leaving poverty.

First is the call for improved levels of infrastructure development. The 221 poor households in four major poor areas of Huangpi faced uneven individual development and weak economic power. Most villagers had a regular source of income, which usually comes from government subsidies. Poor households and government managers in Huangpi District paid little attention to the development of socio-technical infrastructure. As a result, farmers urge improvements to village roads, day-care centres and other infrastructure and production greenhouses.

Second, they demand for employment promotion and income improvement. 221 poor households had a per capita disposable income below the 2020 national income level standard of RMB 4,867. Of these, business income, such as opening shops and trading, accounts for a small proportion. There is a growing need for poor households to seek more employment opportunities to improve their quality of life and secure a source of income.

Third, they need more resource. They are basically in a cool climate zone, where although the geographical area is large, arable land is small. Furthermore, the low fertility of the local soil had also led to consistently low yields in crop cultivation.

Fourth, information technology should be provided. Facing the leading causes of poverty, such as the lack of technology and capital, the local poor were generally eager to master basic scientific and technological knowledge by themselves and learn to use technology to guide their production life. They were also willing to implement Chinese specialty cash crops, grow and process them, and independently develop local primary agricultural raw materials and package them for export to continuously extend the industrial chain and make the poor households never return to poverty.

Finally, they hope to improve the level of constructing beautiful and livable villages. In the face of significant events in village collectives, such as the construction of collective sanitation facilities. Most village collective enterprises had zero income from economic operations, which discouraged them to participate in the cultural construction of beautiful and livable villages, but the majority of poor households still hoped that the government would increase its management efforts and continuously improve the construction of beautiful and livable villages

\section{POTENTIAL RISKS OF POVERTY RETURN}

Based on the survey in the previous section, it was found that there would still be potential risks which would cause poverty again. The following explores specifically the reasons why households leaving poverty would return to poverty.

\subsection{The Lack of Education}

Poverty does not simply refer to falling below the recognized standard of poverty at the material level but also to the difficulties caused by the poor's lack of capacity and literacy, which is an inherent obstacle for poor families to escape poverty. $35.6 \%$ of the poor households found it difficult to earn a stable income from their work due to the lack of skills that prevent them from implementing professional breeding and entrepreneurial enrichment. The overall development of poor households was at the lowest levels of education and literacy, mainly illiterate and semi-literate, with the relationship between the proportion of students increasing and decreasing with education. The overall impact of poor households on education was the same as at the secondary level and above. The proportion of non-poor households at the lower secondary level and above was slightly higher than the other two rural households. It can be seen that as the level of education increases, the wealth of farmers increases. Generally speaking, farmers' level of education is directly proportional to their wealth.

\subsection{The Influence of Disaster}

Statistics showed that $12.5 \%$ of poor households in Huangpi District were poor due to natural disasters and sudden accidents such as droughts, floods, freezing, hailstorms, landslides and landslides [8]. A basic characteristic of poor households afflicted by disasters is that they either remain in poverty for a long time or remain floating on the edge of poor areas. They can escape poverty temporarily in years when there are no disasters. However, if they encounter a major natural disaster or suffer from a severe natural catastrophe for several years in a row, they face the risk of falling back into poverty. The poor in Huangpi District are mainly located in remote mountainous areas, ecologically fragile areas, disaster-prone areas and ecological reserves. The 
natural environment in these regions is very severe, and the living conditions of villagers are generally poor. The incidence of natural disasters in these regions is also increasing year by year. Agricultural production, the primary economic source of farmers' income, is extremely vulnerable to shocks, reducing or even stopping production, so the problem of poverty due to disasters is particularly prominent.

\subsection{The Impact of Disease}

According to the survey, there is a correlation between poverty and illness. First, the illness of a family member (especially a long-term chronic or significant illness) may deprive the family of an important source of labour and income. It affects the sick person and the work of the family member caring for the sick person. Second, the treatment and rehabilitation of the sick person, especially recuperation and treatment for major and some chronic illnesses, undoubtedly place a heavy financial burden on the family. Therefore, the government should improve the medical insurance policy for the rural population as soon as possible and strengthen the promotion of supplementary medical insurance such as commercial insurance. Social organizations should also actively establish relevant channels for helping and assisting people with major illnesses. Third, the dynamic and timely nature of major illness assistance is very important. Many rural families are unaware of or even completely ignore the policy on major illness assistance and do not understand or have the time and energy to apply for assistance in the relevant areas. This reflects the problems in the communication between policymakers and policy beneficiaries, and whether the communication is timely can lead to a gap between the implementation of the policy and its original intent.

Disability is also a similar cause of poverty to illness. Although it is generally congenital and less sudden than illness, especially major illnesses, it is a less economic shock to the family. However, the impairment of the person with the disability itself may also deprive the family of an important source of labour and income, not only for the person with the disability but also for the family members who care for the person with the disability.

\subsection{Summary of the Causes of the Potential Risks of Returning to Poverty}

For a region, especially a village, infrastructure, transport, and natural conditions are all common factors. Poor households tend to analyze the causes of their poverty from their perspective while downplaying the influence of common regional factors. The improvement of the regional environment will bring more opportunities for poor households to get out of poverty and become richer, such as more high-wage employment opportunities. Many people cannot go out to work because of family factors (such as having elderly children or sick people at home who need care) and their ability, and they miss out on many higher-paying jobs and opportunities to improve their abilities. This provides an important opportunity to improve household income.

Indeed, regional environmental factors have been widely recognized by academics in the study of rural poverty. The current academic research on the causes of regional poverty can be broadly summarized into two views: first, the lack of a developed geographical environment in these areas brings with it remote access and inconvenience, and life-sustainable infrastructure such as communications and energy lags far behind urban areas [9]. These various factors indirectly lead to the under-exploitation of natural resources or an export orientation. The lack of economic development has resulted in widespread poverty. The second is an extreme shortage of natural resources or an irrational structural distribution design. Awareness of regional factors helps address the lack of development incentives in poor areas at a fundamental level. The impact of infrastructure investment and construction is holistic, fundamental. They can greatly change the face of development in poor regions, especially remote and poor mountainous areas, and drive poor regions out of poverty and into wealth. In contrast, the cultivation and development of industries directly impact the improvement of farmers' income.

\section{CONCLUSION}

This work focuses on the practical results of poverty alleviation in Huangpi District, Wuhan, including the number of people lifted out of poverty, the policies for poverty alleviation, and people's satisfaction. By investigating the process and effectiveness of the poverty alleviation policy, this research finds that the poverty alleviation policy in Huangpi were effective. They helped improve poor people' income and living conditions. They may return to poverty again due to the influence of education, disaster, and disease.

By choosing Huangpi District, a poor representative district in Wuhan, as a case study, this paper recognizes the positive impact of policy as well as remain mindful of and some existing problems. Moreover, it puts forward some suggestions that can play a supporting role in deepening the work of precise poverty alleviation in Wuhan and even in Hubei Province. By using the basic poverty alleviation strategy of linking theory to practice, it not only helps to study and enrich theories related to precise poverty alleviation in-depth in the future but also provides field data to support the theory of precise poverty alleviation. 


\section{REFERENCES}

[1] Cao Yang, "Wuhan Huangpi District, Hubei Province: Focusing on "Five Combinations", Improving Quality and Increasing Efficiency to Promote Poverty Alleviation" http://union.china.com.cn/zhuanti/txt/2018-08/28/ content_40479191.html 2018-08-28. Accessed on 04. November, 2021.

[2] Banda, Collium; Van der Merwe, IJ. The ecclesiological significance of the 'African kraal' metaphor in a context of urban poverty in Zimbabwe [J]. Stellenbosch Theological Journal 2017(02): 242 $-267$.

[3] Monem, Mobasser; Baniamin, Hasan Muhammad. Poverty and Governance: An Overview of Bangladesh Experiences [J]. Journal of Regional Studies and Development 2010 (01): 69-89.

[4] Constance Gunhidzirai, Pius T. Tanga. Informal Entrepreneurship as a Poverty Alleviation Mechanism in Zimbabwe: Challenges and Prospects [J]. Journal of Economics and Behavioral Studies 2017 (04): 132-143.

[5] Wang Sangui. China's 40 years of massive poverty reduction: driving forces and institutional foundations [J]. Journal of the Renmin University of China 201832 (06): 1-11.

[6] Jia, Huihui; Lu, Dehong. Research on the effect of financial precision poverty alleviation based on agricultural supply chain [J]. Financial Theory and Practice 2019 (02): 110-118.

[7] Xu, Yining; Liu, Deqin; Wang, Changhai. Analysis of factors influencing satisfaction with precise poverty alleviation projects [J/OL]. Modern Agricultural Science and Technology 2019 (03): 239-240.

[8] Li, Xueping, Liu, Tenglong. The practical dilemma of precise identification in the context of precise poverty alleviation - an example from village $\mathrm{C}$ in the western region of Hubei [J]. Journal of Hubei College of Nationalities (Philosophy and Social Science Edition) 201836 (05):138-144.

[9] Xi Jinping, Escaping Poverty [M]. Fujian People's Publishing House, 2013 